\title{
Development and test of selective sorting grids used in the Norway lobster (Nephrops norvegicus) fishery
}

Madsen, Niels; Holst, René; Frandsen, Rikke; Hansen, Kurt

Published in:

Fisheries Research

Link to article, DOI:

10.1016/j.fishres.2016.10.002

Publication date:

2017

Document Version

Peer reviewed version

Link back to DTU Orbit

Citation (APA):

Madsen, N., Holst, R., Frandsen, R., \& Hansen, K. (2017). Development and test of selective sorting grids used in the Norway lobster (Nephrops norvegicus) fishery. Fisheries Research, 185, 26-33.

https://doi.org/10.1016/j.fishres.2016.10.002

\section{General rights}

Copyright and moral rights for the publications made accessible in the public portal are retained by the authors and/or other copyright owners and it is a condition of accessing publications that users recognise and abide by the legal requirements associated with these rights.

- Users may download and print one copy of any publication from the public portal for the purpose of private study or research.

- You may not further distribute the material or use it for any profit-making activity or commercial gain

- You may freely distribute the URL identifying the publication in the public portal 


\section{Development and test of selective sorting grids used in the}

\section{Norway lobster (Nephrops norvegicus) fishery}

3

4 Niels Madsen ${ }^{1,2 *}$, René Holst ${ }^{3}$, Rikke Frandsen ${ }^{4}$, Hansen Kurt ${ }^{5}$

5

6 University, Fredrik Bajers Vej 7, 9220 Aalborg, Denmark

${ }^{3}$ Department of Biostatistics, Oslo University, Norway 9850 Hirtshals, Denmark

\section{Abstract}

${ }^{1}$ Section of Biology and Environmental Science, Department of Chemistry and Bioscience, Aalborg

${ }^{2}$ Former address: DTU Aqua, National Institute of Aquatic Resources, Denmark

${ }^{4}$ DTU Aqua, National Institute of Aquatic Resources, North Sea Science Park, P.O. Box 101, DK-

${ }^{5}$ SINTEF Fisheries and Aquaculture, North Sea Science Park DK-9850 Hirtshals, Denmark ${ }^{*}$ Corresponding author. Tel.: +45 33963200. E-mail address: nm@bio.aau.dk (Niels Madsen)

Keywords: Bycatch, Nephrops norvegicus, Norway lobster, Selectivity, Sorting grid, Trawl

Due to generally high discard rates in Norway lobster (Nephrops norvegicus) fisheries, a discard ban coming up and to the cod recovery plan in several areas, selective sorting grids have been tested in many areas and are specified by legislation for use in the Kattegat and Skagerrak area bordering Norway, Denmark and Sweden. Grids are very selective, but they can lead to loss of landable Norway lobster and valuable fish species. To improve retention of these species, we developed three new grids using made by polyurethane to make them flexible: One grid had horizontal bars, one had vertical bars, and one had vertical bars and a guiding funnel in front of the grid. Four unselective net bags were used to collect the catch escaping through different parts of the grid or escaping without passing through the grid. Water flow around the grid bars was measured in a 
flume tank. The three grids were tested from a commercial trawler in the Kattegat and Skagerrak area. Underwater filming was conducted to assess grid performance and fish behavior. Results showed that a bottom hole in the lower part of the grid allowed species in the lower part of the gear to pass and retained in the bag behind the hole. More flatfish passed the grid with horizontal bars compared to that with vertical bars, but the retention rate was still low. Use of the guiding funnel increased the contact with the grid considerably for both target and unwanted species. In all three grid designs, there were losses of Norway lobster above minimum landing size.

\section{Introduction}

The Norway lobster (Nephrops norvegicus) fishery is among the most economically important demersal species for human consumption in European fisheries (Catchpole and Revill, 2007). To retain Norway lobster, the mesh sizes used are relatively small (normally below $100 \mathrm{~mm}$ ), which results in high bycatch and discard rates in most Norway lobster fisheries (Catchpole and Revill, 2007) and concern about the effects of this fishery on declining stocks of other species, particularly cod (Gadus morhua) (Madsen and Valentinsson, 2010; Eliasen, 2014). Additionally, the high bycatch rates in Norway lobster fisheries will cause problems by the reform of the European Union common fisheries policy that plans for gradual elimination of discards by landing obligations where all individuals of certain species caught are landed (Sardà et al., 2015). This means that unwanted catch (i.e., species or sizes with landing obligations but not of commercial interest) will be attributed to a given vessel's quota.

Results of several experiments from different fisheries indicate that sorting grids can be very selective and help reduce the volume of unwanted bycatch species in the catch of Norway lobster fisheries (Catchpole et al., 2006; Graham and Fryer, 2006; Loaec et al., 2006; Valentinsson and Ulmestrand, 2008; Frandsen et al., 2009; Drewery et al., 2010). Their use has been introduced by legislation in the Skagerrak and Kattegat (Valentinsson and Ulmestrand, 2008; Frandsen et al., 2009; Madsen and Valentinsson, 2010), and the grids are widely used by Swedish fishermen fishing 
in this area, whereas Danish fishermen use other selective devices (Madsen and Valentinsson, 2010).

Several studies reported a loss of marketable fish bycatch when grids were used in the Norway lobster fishery (Catchpole et al., 2006; Frandsen et al., 2009; Drewery et al., 2010). The fish bycatch constitutes a part of the economy in most Norway lobster fisheries, particularly flatfish species. A loss of commercial sized Norway lobster also has been identified (Frandsen et al., 2009). Thus, improvements of grids in order to retain commercial fish species and lobster are essential.

Some studies have focused on improving the performance of the grid (Valentinsson and Ulmestrand, 2008; Frandsen et al., 2009; Madsen et al., 2010). Results indicate that it is possible to make improvements but also that further development is necessary. In relation to increasing sustainability in the Norway lobster fishery by reducing unwanted bycatches, the upcoming discard ban and an environmental certification (e.g., Marine Stewardship Council; www.msc.org) that may be required of these fisheries. It is thus crucial to improve the grid to make it commercially feasible because of the expected increased use of grids by fishermen in the future. The main objective of this study was to develop and test an improved grid system that is able to increase the retention of marketable fish and Norway lobster but still be highly selective to nontarget species. Most previous studies have been conducted based on relative catch comparisons (Catchpole et al., 2006; Valentinsson and Ulmestrand, 2008; Drewery et al., 2010), in which results depend on the size structure of the populations that come in contact with the grid. In this study we used small meshed collecting bags to provide estimates that were population independent. By covering different parts of the grids with the collecting bags we aim at gaining information about where escape takes place. The experiments were conducted in the Kattegat and Skagerrak area, which is characterized by high discard rates (Feekings et al., 2012; Uhlmann et al., 2014) and where management plans have been made to ensure recovery of the cod stock that has been declining over the past 30 years (Madsen and Valentinsson, 2010; Kraak et al., 2013; Eliasen, 2014). During the last decade, development and implementation of selective fishing gears has been a cornerstone of fisheries management in this area (Madsen and Valentinsson, 2010). 


\section{Materials and methods}

\subsection{Grid development}

The grid designs are illustrated in Fig. 1. To avoid fishermen safety issues and improve handling

properties, the grids were not constructed of metal. Instead, they were made of polyurethane

(Carlsen Nets, Denmark) that is very strong and able to sustain temperatures from -30 to $70{ }^{\circ} \mathrm{C}$.

This material is flexible, making it possible to wind it directly on the net drum.

To improve the performance of the grid, several changes were made compared to the grid specified by legislation and the grids tested in previous experiments (Valentinsson and Ulmestrand, 2008; Frandsen et al., 2009; Madsen and Valentinsson, 2010; Madsen et al., 2015). First, the grid colour was black to provide a potential contrast effect (Glass and Wardle, 1995; Glass et al., 1995) so that fish might react by trying to avoid the bars and swim out. Second, the bar distance was increased to $45 \mathrm{~mm}$ from the $35 \mathrm{~mm}$ required by legislation (Madsen and Valentinsson, 2010) and the $40 \mathrm{~mm}$ tested in previous experiments (Madsen et al., 2015). This change was aimed particularly at reducing loss of Norway lobster above minimum landing size (MLS). Third, a hole

99 (henceforth bottom hole) was made in the lowest part of the bottom of the grid having only two bars left to guide fish away, particularly cod. The purpose of this hole was to stop benthic debris from blocking the bars in an area which is essential for the passage of Norway lobster, to allow a substantial proportion of Norway lobster to enter the codend (Madsen and Hansen, 2001) without coming into physical contact with the grid, and to let commercial important ground fish 104 (particularly flatfish) enter the codend directly. The height of the bottom hole was increased from $15 \mathrm{~cm}$ in a past experiment (Madsen et al., 2015) to $17.5 \mathrm{~cm}$. Two designs of the grid were 
to make it easier for flatfish to pass through the bars since they are of commercial importance in the Danish Norway lobster fishery (particularly plaice).

The grids were inserted at an angle of $45^{\circ}$ in a four-panel section made of $90 \mathrm{~mm}$ single thread polyurethane (Fig. 2). A four-panel section was used because it is expected to be more stable than a traditional round two-panel section (Madsen et al., 2010). A wedge section inserted in front of the grid section served as the conversion to the conventional two-panel sections in front of the grid section. The vertical bars grid was tested in two different riggings: one without a guiding funnel and one with a 2 meter long guiding funnel ending $70 \mathrm{~cm}$ in front of the grid having a vertical opening on $20 \mathrm{~cm}$ (Fig. 2). The advantage of using a guiding funnel is that the catch is concentrated in the lower part of the fishing gear, potentially providing a larger contact area for Norway lobster that might hit the middle or upper part of a grid (Krag et al., 2009). The disadvantage is that the funnel disrupts behavior, particularly by guiding fish downwards, and reduces the use of species-specific behavior as a selectivity tool (e.g., cod are expected to stay higher in the net than Norway lobster and flatfish).

Four $8 \mathrm{~m}$ long separate small meshed collecting bags made of netting with a $35 \mathrm{~mm}$ nominal mesh opening were inserted in the codend and attached to the grid where they were used to collect fish penetrating and escaping from the grid system (Fig. 3). The bags collected individuals escaping through: 1) the hole in the lower part of the grid; 2) the lower half of the grid; 3) the upper half of the grid; and 4) the escape hole above the grid after being rejected by the grid system.

\subsection{Experimental work}

All grid systems were tested in a flume tank (Hirtshals, Denmark) to assess performance and make adjustments before the sea trials. Approximately 20 fishermen and net markers participated in these tests to comment and discuss the performance of the systems. Measurements of the water flow inside the codend were conducted at the maximum speed for the flume tank of $0.9 \mathrm{~m} / \mathrm{s}$ (1.8 knots), using an electromagnetic current flow sensor (Valeport, model 802) with a precision of flow 
measurements $\pm 4 \%$. The measurements were taken $10 \mathrm{~cm}$ in front of the grid and midway in the

135

136

137

138

vertical direction for the hole, the lower grid and the upper grid sections (Fig. 2). Measurements were also taken $10 \mathrm{~cm}$ behind the grid at the same positions for the two vertical bars grids; this measurement was not taken for the horizontal bars grid because it was impossible to penetrate this grid (from above) with the flow meter. A total of 1000 measurements were taken at each position.

Experimental sea trials were conducted in March 2010 in the Kattegat and Skagerrak area from a 20 m long commercial stern trawler (vessel number: FN 234) with an engine power of $298 \mathrm{~kW}$. The trawler was rigged with a twin trawl system that fishing with its own two identical trawls made for the fishery in this area that mainly targets Norway lobster, having a nominal $100 \mathrm{~mm}$ mesh size throughout, 460 meshes in circumference, a horizontal opening around $20 \mathrm{~m}$ and a headline height around $2 \mathrm{~m}$. The grid with horizontal bars was fished on one side of the twin trawl system, and the other side was used for other experiments. The grid with vertical bars and the grid with vertical bars and guiding funnel were fished simultaneously in each side of the twin trawl system. For all three grid systems the side position in the twin trawl system was change midway during the sea trials.The towing time varied from around 2 to 4 hours. This duration was on the low end compared to most commercial fisheries, but it was chosen to minimize the risk of potential blocking of the grids by debris that would obscure the selective effect of the grid and blur the results.

To obtain the total catch weight, the cover fractions were weighed using a crane scale (Kern HTS 1.5T, Germany) on deck, and then the weight of the netting was subtracted. Length measurements were taken for all commercially important species, and all individuals were length measured in most cases. However, subsampling was necessary for haddock (Melanogrammus aeglefinus), whiting (Merlangius merlangus), and Norway lobster when catches were high. The total length of fish were measured to the nearest $\mathrm{cm}$ below and Carapace length of Norway lobster to the nearest mm using an electronic calliper (Sylvac S_cal pro, Switzerland). The midpoints (mean) of the length classes of fish and Norway lobster were used in the subsequent analysis.

Underwater video observations (Camera: Inspecam SHF; Control Box WP; www.u-cam.com) of the grid were conducted for two hauls during fishing on the Norway lobster grounds where the 
161

162

163

164

165

166

167

168

169

170

171

172

173

$$
\operatorname{logit}(\varphi(\ell)) \approx \log \left(\frac{q_{t}}{q_{c}}\right)+\beta_{0}+\beta_{1} \cdot \ell+\cdots+\beta_{k} \cdot \ell^{k}
$$

174 for some integer $k$. Here $\log \left(\frac{q_{t}}{q_{c}}\right)$ acts as an offset, where $q_{t}$ and $q_{c}$ denote the proportions of the 175

$$
\operatorname{logit}\left(\varphi_{j}(\ell)\right) \approx \log \left(\frac{q_{j}}{q_{0}}\right)+\beta_{0, j}+\beta_{1, j} \cdot \ell+\cdots+\beta_{k, j} \cdot \ell^{k}, j=1, \ldots, J-1
$$



demanding in terms of number of fish caught in each compartment. Furthermore, the model is subject to the same limitations of confounding between the intercepts and the split-parameters.

The well-known between-haul variation (Fryer, 1991) that occurs when data are collected over multiple hauls was addressed by applying the $\sqrt{\text { REP }}$ correction to the standard errors of the parameters estimates obtained from fitting the above model to the stacked data (Millar et al., 2004). This approach is robust for handling data with scarce observations in individual haul compartment combinations. Confidence bands for the expected proportions were obtained using the delta theorem (Lehmann, 1983). We used the R-package 'nnet' for the estimation of our model.

\section{Results}

\subsection{Flow measurements}

The flume tank tests indicated that the grids and the experimental set-up using collecting bags worked very well after a few adjustments. Flow measurements are provided in Table 1. The flow was highest in front of the lower grid, followed by the hole and then the upper grid. The flow was reduced by $<10 \%$ at the lower grid and by $\sim 25 \%$ at the upper grid compared to the free stream. 
areas without any seaweed. Hauls where seaweed was found on the grid were discarded because its presence reduced penetration through the bars and hence influenced selectivity. In the remaining hauls seaweed was not observed on the grid or in collecting bags. One haul was discarded because a large amount ( $>5$ tonnes) of greater weaver (Trachinus draco) was caught. Table 2 lists the number of hauls included in the analysis (10-14) for each grid system and conditions during the sea trials. Total catch weights (all four fractions) varied from 207 to 528 kg for the horizontal bars grid, 375$1034 \mathrm{~kg}$ for the vertical bars grid and 307-1289 kg for the vertical bars grid with a guiding funnel.

Pooled catches of the different species and their distribution in the four compartments are provided in Table 3. The escape of Norway lobster below MLS was (17.4\%) in the vertical bars grid without the guiding funnel, and of about the same magnitude for the horizontal bars grid (5.4\%) and vertical bars grid with the guiding funnel (5.8\%). The escape of Norway lobster above

MLS was $12.8 \%$ in the vertical grid with a guiding funnel, $32.5 \%$ in the vertical bars grid without the guiding funnel; the value was $24.1 \%$ for the horizontal bars grid. The proportion of Norway lobster above MLS passing through the bottom hole in the grid with horizontal bars, vertical bars and vertical bars with guiding funnel was $44.1 \%$, $25.8 \%$ and $66.6 \%$.

The average escape of cod, haddock, and whiting below MLS was high (67.3-88.0\%) in the horizontal and vertical bars grid without the guiding funnel. Escape of cod and whiting above MLS in the vertical bars grid and the horizontal bars grid was high (82.6\%-92.6\%). A high proportion of plaice (77.3\% and 92.4\%) above MLS escaped from the horizontal and vertical bars grid without the guiding funnel, respectively.

Relatively few cod, haddock, and whiting passed through the bars of the three grids, but those that did so passed through both the lower and upper grid. The proportion of cod, haddock and 233 whiting below MLS passing through the bottom hole in the grid with horizontal bars, vertical bars 234 and vertical bars with guiding funnel was from 5.3-11.0\%, 2.2-7.6\% and 39.5-46.1\%, respectively. 
For plaice above MLS the proportion passing through bottom hole for the horizontal bars grid, the vertical bars grid and the vertical bars grid with guiding funnel was $14.4 \%, 5.8 \%$ and $45.6 \%$, respectively and for lemon sole the numbers were 5.7\%, 2.9\% and 24.3\%.

\subsection{Modeling of proportions}

Fig. 3 shows the expected proportions of the catch by length in each of the four compartments for the three different grid designs (with 95\% confidence bands). For cod a lower proportion escaped from the vertical bars grid with the guiding funnel compared to the two other grids, and the difference was statistically significant for fish below $30 \mathrm{~cm}$ (hereafter, statistical significance is indicated by lack of overlap of the $95 \%$ confidence limits). Additionally, the proportion of cod that entered the bottom hole was significantly higher in the range from 20 to $60 \mathrm{~cm}$. The proportion of haddock escaping from the horizontal bars grid was statistically significantly higher for fish below $30 \mathrm{~cm}$ compared to the two other grids. No statistically significant difference in escape from the three grids was detected for lemon sole above $30 \mathrm{~cm}$. There is a higher (statistically significantly) escape in the vertical bars grid compared to the horizontal bars grid for lemon sole below $20 \mathrm{~cm}$. A high proportion, but rapidly decreasing with length, of the smallest lemon sole entered the lower grid of the vertical bars grid with the guiding funnel. The proportion of escapees of Norway lobster increased with length for all three grids. At around $50 \mathrm{~mm}$ carapace length, the proportion escaping was significantly lower for the vertical bars grid with the guiding funnel compared to the other two grids. The proportion of plaice in the bottom hole section was statistically significantly higher for all lengths for the vertical bars grid with the guiding funnel compared to the two other grids. The escape of whiting below MLS is significantly lower in the vertical bars grid with guiding funnel.

\subsection{Underwater observations}


The observations were limited when fishing on Norway lobster fishing grounds because of clouds of mud. However, it was possible to observe the grid with horizontal bars for limited periods 264 of time. Three flatfish were observed to be sitting on the grid throughout the observation period. 265 Flatfish approached the grid horizontally with the head either facing directly upstream or downstream (not sidewards). One plaice facing downstream drifted towards the grid and, upon contact, flipped its tail, which resulted in escape through the escape hole in the upper sheet of netting. Two flatfish, one facing upstream and one facing downstream, passed between the bars of the grid, and another flatfish passed through the bottom hole. Only three round fish appeared on the footage. They were all facing upstream, and no contact with the grid was observed. No Norway lobsters were observed.

No fish were observed sitting on the grid with vertical bars for a long period of time. Those fish that stayed on the grid did not slide along the bars passively. Flatfish were able to stay in positioned in front of the grid. In a 5 minutes observation period with good visibility there were 71 flatfish passing through the guiding funnel; 75 observations of flatfish (often the same individual) reacting with a few extra tail beats if they touched the grid; 12 flatfish passing between the bars tail first; 36 flatfish drifting along the bottom and passing through the bottom hole. A single plaice facing downstream passed through the grid head first. Small round fish stayed positioned in front of the grid. They seemed to be moved slowly upwards by the flow and ended up escaping through the escape hole. A larger gadoid hit the grid, and it reacted with rapid tail beats and ended up passing between the bars of the grid tail first.

\section{Discussion}

In general, we documented high escape of fish in the two grid concepts in which no guiding funnel was used. We used an experimental codend/collecting bags with small low-selective meshes. In a commercial codend, mesh selection will occur in the codend behind the grid, where additional 
escape of some of the smallest fish passing through the grid system will occur. The bottom hole seemed to function well in the grids without the guiding funnel, as a relatively high proportion of Norway lobster entered through it, as did a few gadoids. Because the proportion of flatfish was low, it would be relevant to make improvements to retain more flatfish above MLS that are of commercial value. In all grids tested in our experiments, higher proportions of cod, plaice and Norway lobster above MLS entered the bottom hole, compared to a previous experiment (Madsen et al., 2015) having a bottom hole with a lower height $(17.5 \mathrm{~cm}$ vs $15.0 \mathrm{~cm})$ and with more bars (6 versus 2).

Use of the guiding funnel increased the proportion of the catch that passed through the hole in the bottom of the grid where they were not subjected to size selectivity caused by grid bars. For cod, more than half of the catch above MLS passed through the hole. For a grid with bars instead of a hole in the lower part, a guiding funnel is an efficient way to increase the contact with the grid in the lower part.

The flow in front of the lower part of the grid was not much lower than that of the free steam flow, whereas some reduction was detected in front of the upper grid that might be caused by an upward flow in the direction of the escape hole in the top panel. We observed that relatively large fish demonstrated avoidance behavior near the grid, but this occurred when the visibility in the water was high. Most Norway lobster fisheries are located in deeper water, where the visibility is low due to mud clouds. Smaller individuals with lower swimming performance (Videler and Wardle, 1991) will be less able to react to the grid. Norway lobster is expected to mainly stay in the lower part of the gear (Cole and Simpson, 1965; Main and Sangster, 1985; Krag et al., 2009), and because they have limited swimming ability (Newland et al., 1988; Newland and Chapman 1989), it is likely that their first contact will be with the lower part of a grid device. The water flow, and hence the towing speed, might have an effect on the selection process, but it is not obvious in which direction, and further investigations would be valuable.

More plaice above MLS passed through the horizontal bars compared to the vertical bars. However, still more than three-quarters of the plaice above MLS escaped when using horizontal 
bars. A high rejection rate of flatfish that come in contact with grid bars must be expected, and it will be difficult to increase substantially the retention rate of large flatfish and other selective devices should be considered to increase retention of flatfish. As observed in previous trials with other grid designs and the $35 \mathrm{~mm}$ bar distance (Frandsen et al., 2009) and $40 \mathrm{~mm}$ bar distance (Madsen et al., 2015) there are still Norway lobster that don't penetrate the grid and escape. For the horizontal bars grid, only around 5\% of Norway lobster below MLS escaped whereas 24\% above MLS escaped. This indicates that it is actually possibly to reduce the loss further by increasing the bar distance. Because a proportion of the Norway lobster catch passes through the upper part of the grid, another potential way to reduce loss is to increase the length of the grid and to increase the contact area, as penetration of Norway lobster through the grid bars will depend on the contact angle (Frandsen et al., 2010) and several escape attempts might be necessary. However, increased length of the grid is expected to increase retention of small fish.

We conducted relatively short hauls, but we still had to discard several hauls because the grids were blocked by seaweed. This is a disadvantage of the grid compared to selective escape windows. Under commercial conditions, this problem might add an extra cost for the fishermen, and in some areas it might be impossible to use a grid during certain periods of time. However, it might be possible to find a technical solution to this problem. For example, in shrimp fisheries, sensors on the grid are often used to indicate the water flow through the grid. If the grid becomes blocked, the 334 skipper makes a short stop to lower the grid to a horizontal position to remove trash from the grid. Although this particular solution is not very likely to work for seaweed that has infiltrated the grid, similar approaches should be investigated to find a way it would likely remove. In addition, it likely would work to remove other objects, such as flatfish, that can get stacked on the grid.

Grids made of polyurethane tested in this study are currently used by several fishermen in shrimp 339 fisheries in several areas, , and they are satisfied with its performance. The stiffness of the material can be adjusted during the production. The general experience is that the "memory" of the material is limited, which ensures that the grid returns to its original shape after being on the net drum. "The 
342 grids made of this material will likely meet the needs of fishermen in terms of improved handling 343 and safety compared with metal grids."

Acknowledgement

Thanks are particularly due to Carlsen Net, SINTEF technicians, the crew of Canopus, and our colleagues and two anonymous referees for commenting on the manuscript. This work was conducted with the financial support of the European Union and the Danish Ministry of Food, Agriculture, and Fisheries.

\section{References}

Catchpole, T.L., Revill, A.S., 2007. Gear technology in Norway lobster trawl fisheries. Reviews in Fish biology and Fisheries 18, 17-31.

Cole, H.A., Simpson, A.C., 1965. Selection by trawl nets in the Nephrops fishery. Rapp. P.V. Reun. ICES 156, 203-205.

Drewery, J., Bova, D., Kynoch, R.J., Edridge, A., Fryer, R.J., O’Neill, F.G., 2010. The selectivity of the Swedish grid and $120 \mathrm{~mm}$ square mesh panels in the Scottish Nephrops trawl fishery. Fish. Res. 106, 454-459.

Eliasen, S.Q., 2014. Cod avoidance by area regulations in Kattegat - experiences for the implementation of a discard ban in the EU. Mar. Pol. 5, 108-113.

Feekings, J., Bartolino, V., Madsen, N., Catchpole, T., 2012. Fishery discards: Factors affecting their variability within a demersal trawl fishery. PLoS One, 7(4): e36409. 
Frandsen, R.P., Herrmann, B., Madsen, N., 2010. A simulation-based attempt to quantify the morphological component of size selection of Nephrops norvegicus in trawl codends. Fish. Res. 101, 156-167.

Frandsen, R.P., Holst, R., Madsen, N., 2009. Evaluation of three levels of selective devices relevant to management of the Danish Kattegat-Skagerrak Nephrops fishery. Fish. Res. 97, 243-252.

Fryer, R.J., 1991. A model of the between-haul variation in selectivity. ICES J. of Mar. Sci. 48, 281-290.

Glass, C.W., Wardle, C.S., 1995. Studies on the use of visual stimuli to control fish escape from codends: II. The effect of a black tunnel on the reaction behaviour of fish in otter trawl codends. Fish. Res. 23, 165-174.

Glass C.W., Wardle, C.S., Gosden, S.J., Racey, D.N., 1995. Studies on the visual stimuli to control fish escape from codends: I. Fish. Res. 23, 157-164.

Graham N., Fryer R.J., 2006. Separation of fish from Nephrops norvegicus into a two-tier cod-end using a selection grid. Fish. Res. 82, 111-118.

Holst, R., Revill, A., 2009. A simple statistical method for catch comparisons studies. Fish. Res. 95, 254-259.

Kraak, S.B.M., Bailey, N., Cardinale, M., Darby, C., De Oliveira, J.A.A., Eero, M., Graham, N., Holmes, S., Jakobsen, T., Kempf, A., Kirkegaard, E., Powell, J., Scott, R.D., Simmonds, J.E., Ulrich, C., Vanhee, W., Vinther, M., 2013. Lessons for fisheries management from the EU cod recovery plan. Mar. Pol. 37, 200-213.

Krag, L.A., Madsen, N., Karlsen, J.D., 2009. A study of fish behaviour in the extension of a demersal trawl using a multi-compartment separator frame and SIT camera system. Fish. Res. 98, 62-66.

Lehmann, E.L., 1983. Theory of point estimation. Wiley \& Sons Inc., 511 pp.

Loaec, H., Morandeau, F., Meillat, M., Davies, P., 2006. Engineering development of flexible selectivity grids for Nephrops. Fish. Res. 79, 210-218. 
Madsen, N., Frandsen, R.P., Holst, R., Krag, L.A., 2010. Development of new concepts for escape windows to minimise cod catches in Norway lobster fisheries. Fish. Res., 103: 25-29.

Madsen, N., Hansen, K.E., 2001. Danish experiments with a grid system tested in the North Sea shrimp fishery. Fish. Res. 52, 203-216.

Madsen, N., Lewy, P., Feekings, J., Krag, L.A., Frandsen, R., Hansen, K., 2016. Improving the performance of a grid used in Norway lobster fisheries. J. Appl. Ichthyol. 31, 525-528.

Madsen, N., Valentinsson, D., 2010. Use of selective devices in trawls to support recovery of the Kattegat cod stock: a review of experiments and experience. ICES J. Mar. Sci. 67, 2042-2050.

Main, J., Sangster, G.I., 1985. Trawling with a two-level net to minimise the undersized gadoid bycatch in a Nephrops fishery. Fish. Res. 3, 131-145.

Millar, R.B., Broadhurst, M.K., Macbeth, W.G., 2004. Modelling between-haul variability in the size selectivity of trawls. Fish. Res. 67, 171-181.

Newland, P.L., Chapman, C.J., Neil, D.M., 1988. Swimming performance and endurance of the Norway lobster, Nephrops norvegicus. Mar. Biol. 98, 345-350.

Newland, P.L., Chapman, C.J., 1989. The swimming and orientation behaviour of the Norway lobster, Nephrops norvegicus (L.), in relation to trawling. Fish. Res. 8, 63-80.

Sardà, F., Coll M., Heymans, J.J., Stergiou, K.I., 2015. Overlooked impacts and challenges of the new European discard ban. Fish Fish., 16, 175-180.

Wang, H., 2008. Exact confidence coefficients of simultaneous confidence intervals for multinomial proportions. Journal of Multivariate Analysis 99, 896-911

Uhlmann, S.S., van Helmond, A.T.M, Stefánsdóttir, E.K., Sigurðardóttir, S., Haralabous, J., Bellido J.M., Carbonell, A., Catchpole, T., Damalas, D., Fauconnet, L., Feekings, J., Garcia, T., Madsen, N., Mallold, S., Margeirsson, S., Palialexis, A., Readdy, L., Valeiras, J., Vassilopoulou, V., Rochet, M-J., 2014. Discarded fish in European waters: general patterns and contrasts. ICES J. Mar. Sci. 71, 1235-1245. 
418 Valentinsson, D., Ulmestrand, M., 2008. Species-selective Norway lobster trawling: Swedish grid 419 experiments. Fish. Res. 90, 109-117.

420 Videler, J.J., Wardle, C.S., 1991. Fish swimming stride by stride: speed limits and endurance. Rev. $421 \quad$ Fish Biol. Fish. 1, 23-40.

422 
1 Table 1 . Flow measurements $(\mathrm{m} / \mathrm{s})$ in the flume tank at a $0.9 \mathrm{~m} / \mathrm{s}$ free steam water flow; average with 2 standard deviation (SD).

\begin{tabular}{|c|c|c|c|c|c|}
\hline \multirow[b]{2}{*}{ Grid } & \multirow{2}{*}{$\begin{array}{l}\text { Hole } \\
\text { Front }\end{array}$} & \multicolumn{2}{|l|}{ Lower grid } & \multicolumn{2}{|l|}{ Upper grid } \\
\hline & & Front & Behind & Front & Behind \\
\hline Horizontal bars & $0.80(0.092)$ & $0.83(0.042)$ & Na. & $0.69(0.047)$ & Na. \\
\hline Vertical bars & $0.81(0.11)$ & $0.84(0.066)$ & $0.78(0.077)$ & $0.67(0.081)$ & $0.62(0.052)$ \\
\hline Vertical bars, guiding & $0.79(0.060)$ & $0.87(0.048)$ & $0.71(0.078)$ & $0.65(0.037)$ & $0.63(0.043$ \\
\hline
\end{tabular}

3

4

5 
6 Table 2. Operating conditions during the sea trials; average per haul with standard deviation (SD).

\begin{tabular}{lllll} 
Grid & No. hauls & Haul duration (hrs) & Depth (m) & Speed (kts) \\
\hline Horizontal bars & 10 & $2.88(0.84)$ & $52.2(16.1)$ & $2.51(0.12)$ \\
Vertical bars & 12 & $2.34(0.56)$ & $70.6(14.0)$ & $2.48(0.07)$ \\
Vertical bars, guiding & 14 & $2.52(0.68)$ & $69.6(13.1)$ & $2.49(0.07)$ \\
\hline
\end{tabular}

7

8

9 
Table 3. Catches of the main species for all hauls pooled divided by MLS. Proportions with 95\% confidence limits based on a weighted average of multinomial standard errors over individual hauls (Wang, 2008). No estimates are made (NA) for observations with very low numbers.

\begin{tabular}{|c|c|c|c|c|c|c|}
\hline & \multicolumn{2}{|c|}{ Horizontal bars } & \multicolumn{2}{|c|}{ Vertical bars } & \multicolumn{2}{|c|}{ Vertical bars, guiding } \\
\hline & $<$ MLS & $\geq$ MLS & $<$ MLS & $\geq$ MLS & $<$ MLS & $\geq$ MLS \\
\hline
\end{tabular}

\section{$\underline{\operatorname{Cod}}$}

Total (no.)

Escape

Upper grid

Lower grid

Bottom hole

Haddock

Total (no.)

Escape

Upper grid

Lower grid

Bottom hole

Lemon sole

Total (no.)

Escape

Upper grid

Lower grid

Bottom hole

Norway lobster

Total (no.)

Escape

Upper grid

Lower grid

Bottom hole

Plaice

Total (no.)

Escape

Upper grid

Lower grid

Bottom hole

92
$82.6 \%(67.2-98.1 \%)$
$2.2 \%(0-6.3 \%)$
$1.1 \%(0-3.1 \%)$
$14.1 \%(0-28.4 \%)$

2004

84.7\% (82.1-87.3\%)

$1.1 \%(0.4-1.9 \%)$

$3.2 \%(2.0-4.3 \%)$

$11.0 \%(9.0-12.9 \%)$

$$
\begin{gathered}
3 \\
100.0 \% \text { (NA) } \\
0.0 \% \text { (NA) } \\
0.0 \% \text { (NA) } \\
0.0 \% \text { (NA) }
\end{gathered}
$$

$$
\begin{gathered}
35 \\
85.7 \%(72.1-99.4 \%) \\
8.6 \%(1.1-16.0 \%) \\
0.0 \%(\mathrm{NA}) \\
5.7 \%(0-16.0 \%)
\end{gathered}
$$

540

$24.1 \%(16.1-32.1 \%)$

$12.6 \%(7.1-18.1 \%)$

$19.3 \%(11.9-26.6 \%)$

$44.1 \%$ (34.6-53.5\%)
$85.0 \%(77.4-92.6 \%)$

$5.3 \%(0.8-9.8 \%)$

$3.0 \%(0-6.1 \%)$

$6.7 \%(2.3-11.1 \%)$

1499

$67.3 \%(61.3-73.3 \%)$

$14.9 \%(10.3-19.5 \%)$

$10.2 \%(6.4-14.0 \%)$

$7.6 \%(4.3-10.9 \%)$

139
$89.2 \%(80.2-98.2 \%)$
$2.2 \%(0-5.0 \%)$
$1.4 \%(0-4.1 \%)$
$7.2 \%(0-16.9 \%)$

15

$53.3 \%(36.0-70.7 \%)$ $6.7 \%$ (NA) $6.7 \%$ (NA) $33.3 \%(4.2-62.5 \%)$
611

49.9\% (38.9-60.9\%) $6.5 \%(0.9-12.2 \%)$

$5.4 \%(0-11.0 \%)$

$38.1 \%(28.7-47.6 \%)$

4480 $47.8 \%$ (43.8\%-51.8\%) $2.2 \%(0.9-3.4 \%)$ $3.9 \%(2.1-5.7 \%)$ $46.1 \%(42.1-50.1 \%)$
244

$45.9 \%(30.7-61.1 \%)$

$0.4 \%(0-1.2 \%)$

$0.8 \%(0-2.4 \%)$

$52.9 \%(38.3-67.4 \%)$

144

$35.4 \%(24.9-45.8 \%)$

$0.0 \%$ (NA)

$3.5 \%(0-7.0 \%)$

$61.1 \%(49.3-72.9 \%)$

$$
\begin{gathered}
362 \\
75.1 \%(63.9-86.4 \%) \\
6.9 \%(0-13.9 \%) \\
13.3 \%(6.2-20.3 \%) \\
4.7 \%(0-10.1 \%)
\end{gathered}
$$

780

$17.4 \%(11.2-23.7 \%)$ $25.8 \%(18.5-33.1 \%)$ 26.8\% (19.3-34.3\%)

$30.0 \%$ (22.9-37.1\%)
3463
$78.8 \%(75.8-81.9 \%)$
$2.9 \%(1.5-4.4 \%)$
$1.4 \%(0.4-2.5 \%)$
$16.8 \%(14.4-19.3 \%)$

$85.8 \%(81.3-90.3 \%)$

$4.4 \%(1.8-7.0 \%)$

$2.7 \%(1.0-4.4 \%)$

$7.1 \%(4.3-9.9 \%)$
4917

$\begin{array}{cc}4917 & 1039 \\ 86.8 \%(84.4-89.2 \%) & 88.0 \%(82.7-93.2 \%) \\ 7.7 \%(5.7-9.6 \%) & 5.2 \%(2.1-8.3 \%) \\ 3.4 \%(2.1-4.6 \%) & 3.8 \%(1.2-6.5 \%) \\ 2.2 \%(1.0-3.3 \%) & 3.0 \%(0.4-5.6 \%)\end{array}$

$$
\begin{gathered}
549 \\
55.4 \%(41.7-69.0 \%) \\
5.8 \%(0.1-11.6 \%) \\
8.4 \%(0.9-15.9 \%) \\
30.4 \%(18.4-42.5 \%)
\end{gathered}
$$

846

$5.8 \%(1.7-9.9 \%)$

$9.3 \%(4.6-14.1 \%)$

$20.5 \%$ (13.4-27.5\%)

$64.4 \%(56.1-72.7 \%)$
2860
$34.5 \%(29.3-39.8 \%)$
$1.7 \%(0.2-3.2 \%)$
$5.7 \%(3.1-8.3 \%)$
$58.1 \%(52.8-63.3 \%)$
74

$73.0 \%$ (46.9-99.1\%)

$2.7 \%(0-7.6 \%)$

$0.0 \%$ (NA)

$24.3 \%(0-49.6 \%)$

\section{5}

$12.8 \%(7.9-17.6 \%)$

$8.7 \%(4.7-12.6 \%)$

$11.9 \%(7.2-16.7 \%)$

$66.6 \%$ (59.6-73.6\%)

\section{4}

$50.2 \%(40.4-60.1 \%)$

$1.7 \%(0-3.9 \%)$

$2.5 \%(0-5.5 \%)$

$45.6 \%(36.0-55.1 \%)$

Whiting

Escape

Lower grid

Bottom hole

6766

$54.7 \%(51.1-58.3 \%)$

$1.6 \%(0.6-2.5 \%)$

$4.3 \%(2.6-5.95)$

$39.5 \%$ (36.0-42.9\%)
1975

$48.2 \%(42.1-54.3 \%)$

$0.9 \%(0-2.0 \%)$

$3.0 \%(0.7-5.3 \%)$

$47.9 \%$ (41.9-53.9\%)

MLS: cod (Gadus morhua) $=30 \mathrm{~cm}$; haddock (Melanogrammus aeglefinus) $=27 \mathrm{~cm}$; lemon sole (Microstomus kitt) $=26 \mathrm{~cm}$; Norway lobster (Nephrops norvegicus) $=40 \mathrm{~mm}$ carapace length; plaice (Pleuronectes platessa) $=27 \mathrm{~cm}$; whiting $($ Merlangius merlangus) $=23 \mathrm{~cm}$. 


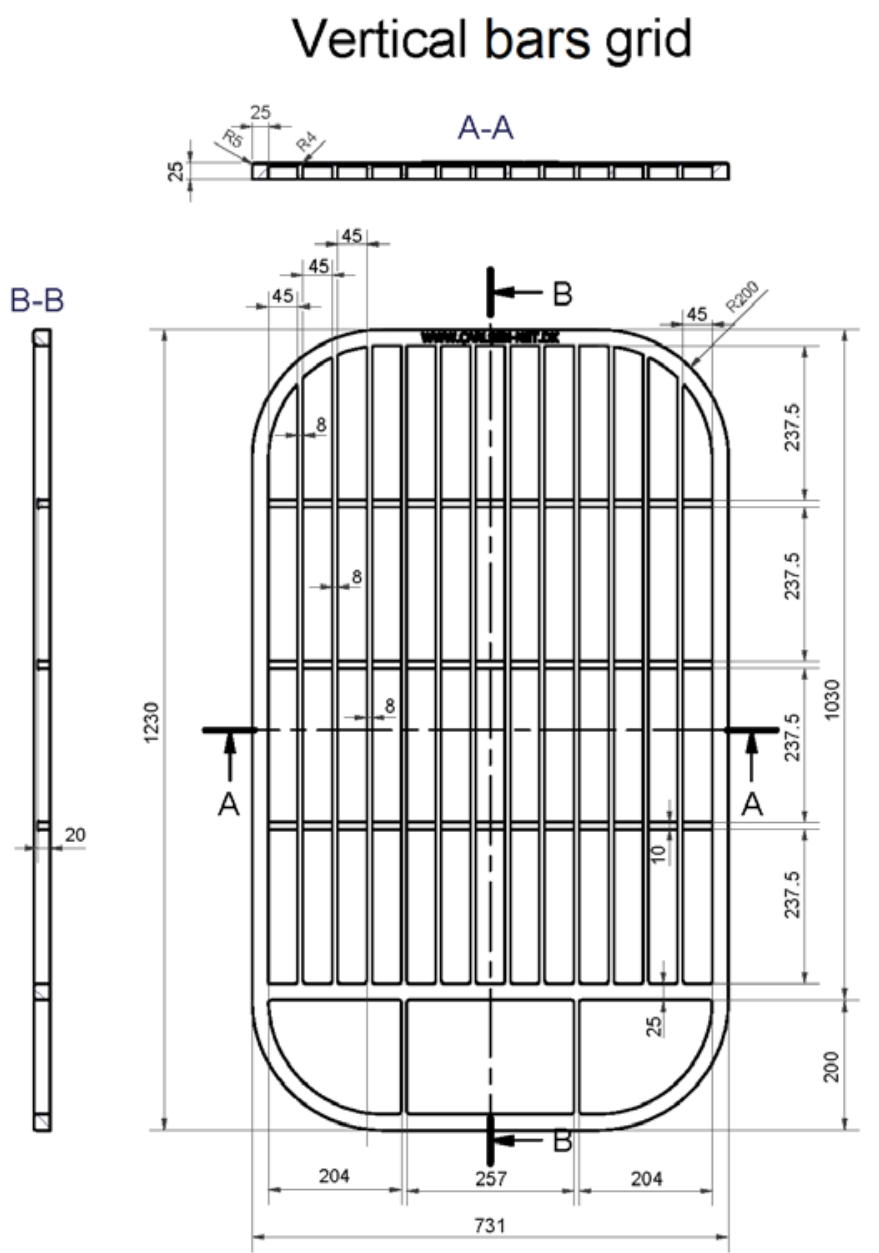

Horizontal bars grid
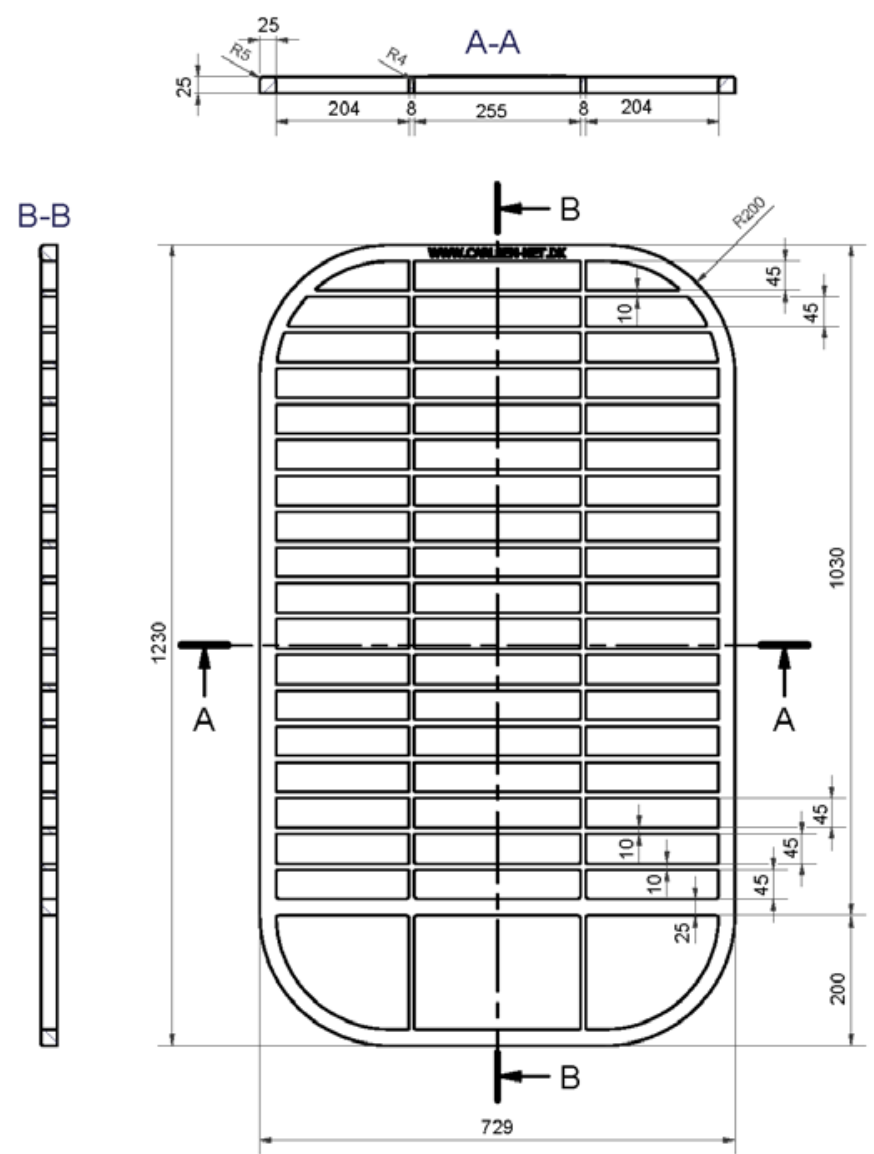

Fig. 1. Technical drawings of the grids. Distances in millimeter. $\mathrm{R}$ indicates the center of afcorner with the corner radius in millimeters. 

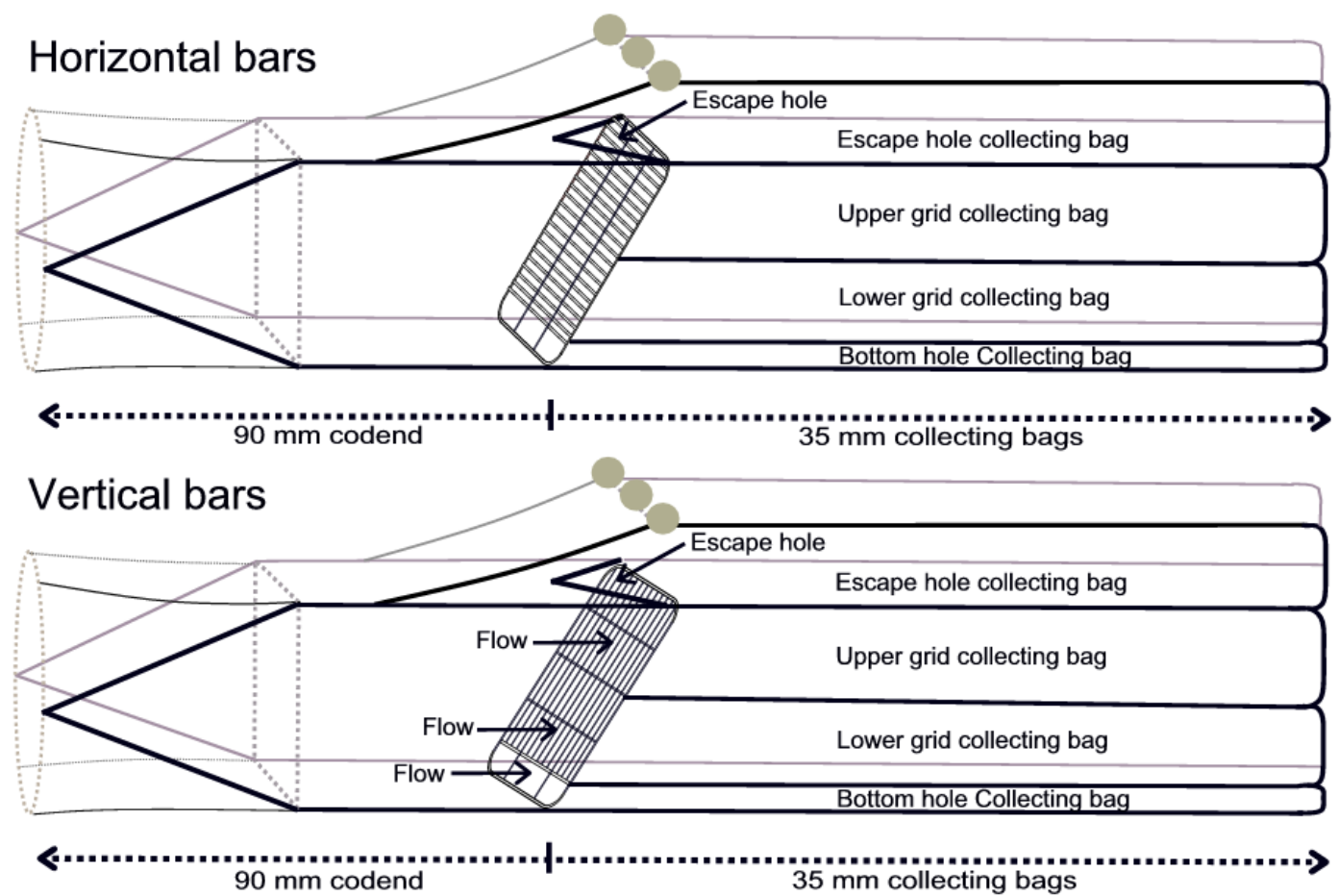

Vertical bars, guiding funnel

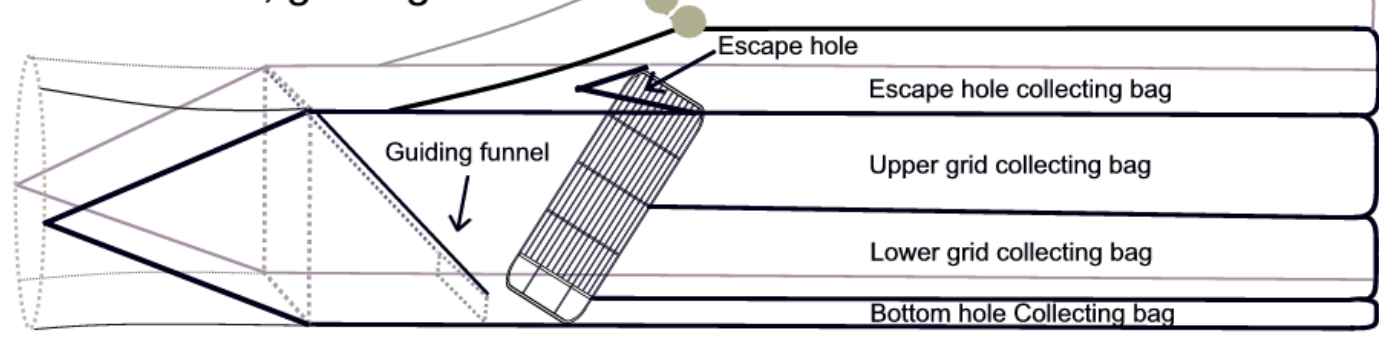
90 mm codend 
Fig. 2. Illustration of the grids and the principles of the experimental design. The $90 \mathrm{~mm}$ mesh size netting was used in front of the grid and the $35 \mathrm{~mm}$ small mesh netting was used for collecting bags that collect fish penetrating the grid system or escaping through the escape hole. Three floats were attached on the top collecting bag above the grid. Positions of flow measurements taken $10 \mathrm{~cm}$ in front and behind the grid (for the grid with vertical bars) are indicated by arrows. Drawing not to scale. 


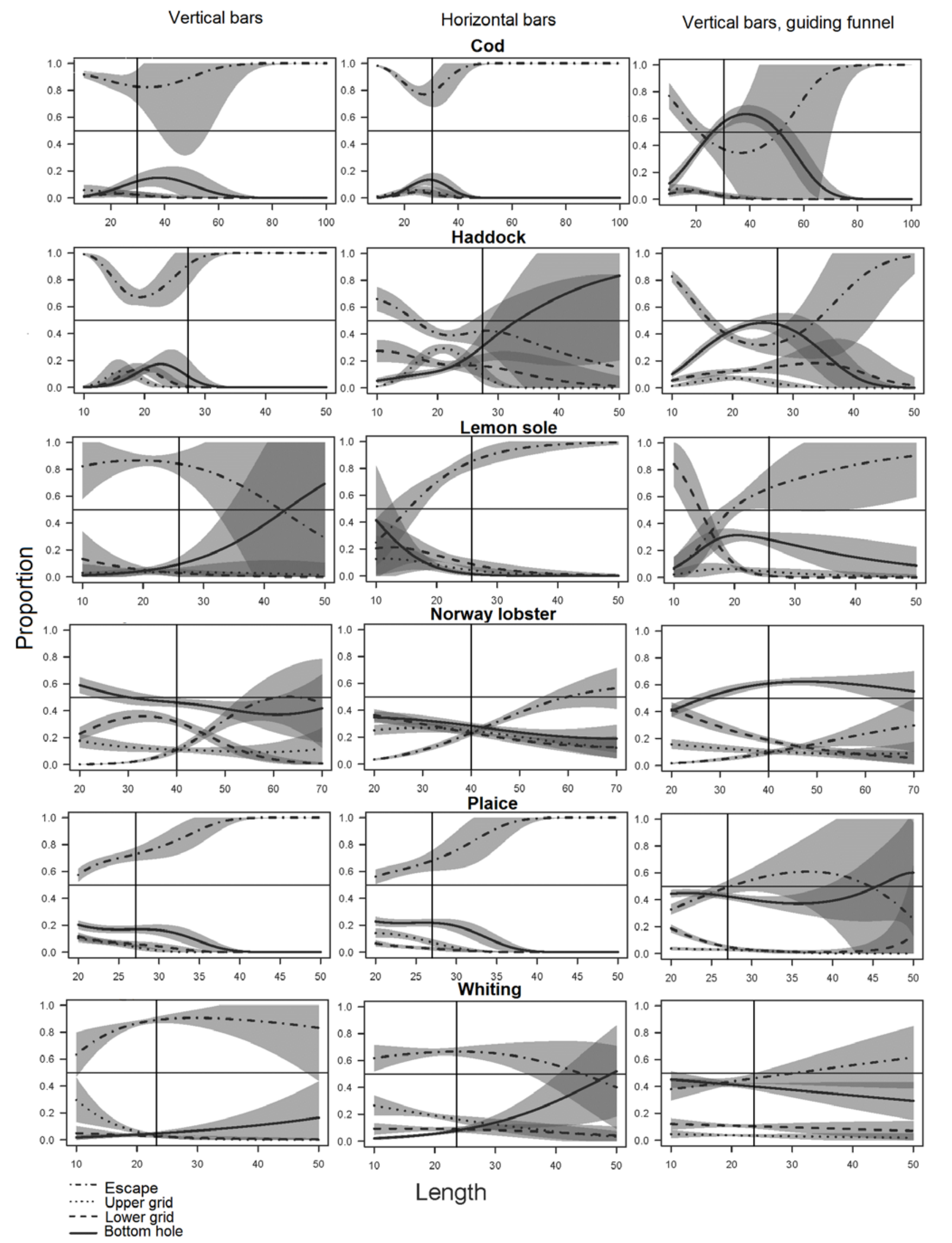

Fig. 3. The proportion by length in each of the four collecting bags for the horizontal grid (left), vertical grid (middle), and vertical grid with guiding funnel (right). The shaded areas indicate the 95\% confidence bandsLength is in $\mathrm{cm}$ for fish and $\mathrm{mm}$ carapace length for Norway lobster. Minimum landing size (length provided in Table 3) is indicated by a vertical line. 